\title{
Validating intrinsic markers and optimizing spot sampling frequency to estimate fecal outputs
}

\author{
D. L. Morris, L. R. Rebelo, P. A. Dieter, and C. Lee ${ }^{1}$ \\ Department of Animal Sciences, Ohio Agricultural Research and Development Center, The Ohio State University, Wooster 44691
}

\begin{abstract}
Indirect methods of spot sampling with intrinsic markers to estimate fecal output and nutrient digestibility often have been used in dairy nutrition research as alternatives to total collection of feces (TC) because of labor and expense. However, fecal output and nutrient digestibility estimated from the indirect method must be accurate regardless of altering dietary conditions. This experiment was designed to validate the accuracy of using indigestible neutral detergent fiber (iNDF) or acid-insoluble ash (AIA) as intrinsic markers to estimate fecal outputs and nutrient digestibility compared with TC and to determine the optimal number of spot sampling events to accurately determine fecal output and then nutrient excretion. The experiment used 12 multiparous lactating Holstein cows in a randomized complete block design. Cows were blocked by days in milk and milk yield and randomly assigned to 1 of 2 diets: a diet containing about $49 \%$ corn silage on a dry matter basis and a diet containing about $48 \%$ alfalfa silage with high by-product (soyhulls) and supplemental K. During the final $3 \mathrm{~d}$ of 21 -d periods, TC was performed, and 12 spot samples were collected for the same $3 \mathrm{~d}$ to represent every $2 \mathrm{~h}$ in a 24 -h cycle. Fecal outputs and nutrient digestibility of dry matter, organic matter, or nitrogen estimated with iNDF or AIA as an intrinsic marker were compared with TC. Overall, fecal outputs and digestibility estimated with iNDF were similar to that estimated with TC, whereas AIA overestimated fecal output by 44 to $61 \%$ and underestimated nutrient digestibilities by 16 to $32 \%$. However, potential differences in statistical inference of dietary effects between iNDF and TC were found. Data from individual spot samples were aggregated to represent spot sampling frequencies of 12 (SP12), 6 (SP6), 4 (SP4), or 2 (SP2) evenly spaced events starting at feeding time. Compared
\end{abstract}

Received March 8, 2018.

Accepted May 27, 2018.

${ }^{1}$ Corresponding author: Lee.7502@osu.edu with TC, SP12 produced similar fecal content of iNDF, organic matter, and nitrogen, but fecal AIA content was greater. Furthermore, compared with SP12, SP6 produced similar fecal content of all nutrients, whereas marker and nutrient concentrations in SP4 and SP2 were different. In this experiment, iNDF was a better fecal marker than AIA, and a spot sampling frequency of at least 6 events was necessary. However, interpretation of dietary effects could be confounded when iNDF was used to estimate fecal outputs.

Key words: fecal output, indigestible neutral detergent fiber, acid-insoluble ash, spot sampling frequency

\section{INTRODUCTION}

Accurate evaluation of dietary effects on fecal outputs and nutrient digestibility is essential for precise estimation of nutrient supply for production and environmental impacts in dairy cows. The most accurate procedure for quantifying fecal output and nutrient digestibility is total collection of feces (TC) that is separated from urine (Schneider and Flatt, 1975). However, TC is laborious and expensive and requires specialized facility that often results in a restriction on the number of animals that are used in experiments. These limitations can be overcome by estimating fecal output using markers. In dairy nutrition, indigestible feed component (i.e., intrinsic markers) have been widely used for estimation of fecal outputs (Van Soest, 1994). Two commonly used intrinsic markers are acid-insoluble ash (AIA) and indigestible NDF (iNDF). Both of these markers have been extensively used across various ruminant species. However, results from studies evaluating the accuracy of estimating fecal output with iNDF and AIA have not been consistent in dairy cows fed various types of diets (Huhtanen et al., 1994; Lee and Hristov, 2013; Kanani et al., 2015).

Accuracy of estimating fecal output with markers can be affected by marker digestibility, passage rate, and analytical errors (Van Soest, 1994). Of equal importance is the collection of samples that are representative of true marker output when utilizing spot sampling. If fecal excretion of internal markers is constant 
throughout a day, the analysis of marker concentration in a single spot sample collected any time during a day would accurately estimate fecal output. However, fecal concentration of markers can be variable throughout a day (Kane et al., 1952; Sampaio et al., 2011). To account for diurnal variation in fecal marker concentration, sampling at multiple time points is required; various sampling frequencies in a 24 -h cycle have been used to estimate total-tract digestibility (Colmenero and Broderick, 2006; Harvatine and Allen, 2006; Lee et al., 2012). However, to our knowledge, the effect of spot sampling frequency on accurate marker representation of fecal iNDF and AIA has not been studied in dairy cows. Lowering sampling frequency within the same marker representation in feces will make experiments less laborious and less stressful to cows.

The objectives of the current study were to confirm the ability of AIA or iNDF as intrinsic markers to estimate fecal output and apparent nutrient digestibility with different types of dairy diets. In addition, spot sampling frequency was optimized for accuracy in representing true fecal marker concentration.

\section{MATERIALS AND METHODS}

\section{Animals and Sample Collection}

The Ohio State University Institutional Animal Care and Use Committee approved animal care and all procedures used in the experiment. The experiment was carried out at the Ohio Agricultural Research and Development Dairy Center (Wooster, $\mathrm{OH}$ ) in a randomized complete block design using 12 multiparous Holstein cows (average \pm SD at the beginning of the trial: DIM, $205 \pm 49 \mathrm{~d}$; milk yield, $29.2 \pm 8.10 \mathrm{~kg} / \mathrm{d}$ ). Cows were blocked by DIM and milk yield, and cows in each block ( 2 cows per block; total of 6 blocks) were randomly allocated to 2 different diets: a diet containing about $49 \%$ corn silage on a DM basis (CS) and a diet containing about $48 \%$ alfalfa silage and high in byproduct (soybean hulls) and supplemental potassium (AS-K; see Table 1). According to the objectives of the current study, the AS-K diet was intended to slightly stimulate fecal output by reducing starch content and increasing by-product in the diet (Pereira and Armentano, 2000; Weiss et al., 2009b). High alfalfa silage and $\mathrm{K}$ were included in the diet to stimulate urinary output (Nennich et al., 2006; Weiss et al., 2009b) for the purpose of our companion study on estimating urine output with creatinine.

The experiment was conducted for $21 \mathrm{~d}$; during the final $3 \mathrm{~d}$, feces and urine were separately collected as described by Weiss et al. (2009a). Total daily excretion of feces from individual cows was weighed, subsampled ( $10 \%$ of daily fecal output on an as-is basis), and composited by cow. Feed offered and refused were quantified daily. Refusals and individual feeds were subsampled and composited (by cow for refusals) daily during the TC period. Additionally, 12 spot fecal samples (from the rectum) were collected during the 3 -d TC period (d 1: 0800, 1400, 2000, 0200 h; d 2, 1000, 1600, 2200, 0400 h; d 3, 1200, 1800, 2400, $0600 \mathrm{~h}$. These spot samples ( $\sim 500 \mathrm{~g}$ of feces) were weighed, and the total fecal output was corrected accordingly. During the 3 -d collection period, DMI for CS and AS-K was 21.8 and $20.9 \mathrm{~kg} / \mathrm{d}$, respectively, and average of daily DMI variation (SD) for CS and AS-K was 0.78 and $1.91 \mathrm{~kg} / \mathrm{d}$. Therefore, feed intake was consistent during the collection period.

\section{Sample Analysis}

Fecal samples from individual spot sampling events and TC, feed ingredients, and refusals were dried $\left(55^{\circ} \mathrm{C}\right.$ for $72 \mathrm{~h}$ ) within $12 \mathrm{~h}$ of collection and ground to pass a 1-mm screen (Wiley mill; Arthur A. Thomas Co., Philadelphia, PA). Dried and ground feces, all feeds,

Table 1. Ingredient composition ( $\%$ of DM unless noted) of diets ${ }^{1}$

\begin{tabular}{lcc}
\hline Item & CS & AS-K \\
\hline Ingredient & & \\
Corn silage & 48.5 & 48.3 \\
Alfalfa silage & - & 4.5 \\
Grass hay & 4.3 & 23.0 \\
Corn grain, ground & 15.7 & - \\
Soybean meal, 48\% CP & 15.5 & 15.1 \\
Soybean hulls & 8.4 & 4.1 \\
AminoPlus & 4.1 & 0.5 \\
Hydrolyzed tallow & 0.5 & 1.4 \\
Potassium chloride & - & 3.1 \\
Mineral/vitamin mix ${ }^{3}$ & 3.0 & \\
Chemical composition & & 51.5 \\
DM, \% as is & 48.1 & 89.0 \\
OM & 92.3 & 16.7 \\
CP & 16.5 & 35.0 \\
NDF & 33.3 & 15.8 \\
Starch & 26.2 & 3.0 \\
Fat & 2.8 & 3.0 \\
K & 1.5 & 9.3 \\
Indigestible NDF & 7.2 & 0.57 \\
Acid-insoluble ash & 0.66 & \\
\hline
\end{tabular}

${ }^{1} \mathrm{CS}=$ corn silage-based diet; AS-K = alfalfa silage-based diet with high by-product and supplemental potassium.

${ }^{2} \mathrm{Ag}$ Processing Inc., Omaha, NE

${ }^{3}$ Contained per kilogram of premix approximately $280 \mathrm{~g}$ of limestone, $250 \mathrm{~g}$ of sodium bicarbonate, $140 \mathrm{~g}$ of trace mineral salt, $20 \mathrm{~g}$ of phosphorus (from monosodium phosphate), $14 \mathrm{~g}$ of magnesium (from magnesium oxide), 1,500 mg of zinc (from Zinpro 120; Zinpro Corp., Eden Prairie, MN), $220 \mathrm{mg}$ of copper (from copper sulfate), $25 \mathrm{mg}$ of biotin, $10 \mathrm{mg}$ of selenium (from sodium selenate), $640 \mathrm{kIU}$ of vitamin E, $110 \mathrm{kIU}$ of vitamin A, and $40 \mathrm{kIU}$ of vitamin D. 
and refusals were analyzed for N (Flash 2000 Elemental Analyzer; Thermo Fisher Scientific, Waltham, MA), AIA (using $2 \mathrm{~N} \mathrm{HCl}$; Van Keulen and Young, 1977), and iNDF (Lee et al., 2012). For iNDF analysis, feces, feed, and refusal samples were weighed into filter bags (25- $\mu \mathrm{m}$ pore size; Ankom Technology Corp., Fairport, NY) and assigned to ruminal incubation for $12 \mathrm{~d}$ using 3 cannulated lactating Holstein cows. The cows were fed once daily at $0800 \mathrm{~h}$ a diet containing the following (DM basis): $37 \%$ corn silage, $10 \%$ alfalfa silage, $5 \%$ alfalfa hay, $8 \%$ cotton seed, $22 \%$ ground corn, $9 \%$ soybean meal, 2.8\% AminoPlus (Ag Processing Inc., Omaha, NE), $2.8 \%$ soyhulls, $0.4 \%$ animal and vegetable fat, and $3 \%$ vitamins and minerals. After incubation, bags were rinsed until the water ran clear and then were analyzed for NDF (Ankom200 Fiber Analyzer; Ankom Technology Corp.) with heat-stable $\alpha$-amylase and sodium sulfite. Samples were not corrected for OM and $\mathrm{N}$ contamination of NDF.

\section{Calculations and Statistical Analysis}

Spot sampling data were averaged to represent a spot sampling frequency of 2 (SP2; 0 and $12 \mathrm{~h}$ after feeding), 4 (SP4; 6, 12, 18, and $24 \mathrm{~h}$ after feeding), 6 (SP6; $4,8,12,16,20$, and $24 \mathrm{~h}$ after feeding), or 12 (SP12; 2 , $4,6,8,10,12,14,16,18,20,22$, and $24 \mathrm{~h}$ after feeding) according to evenly spaced sampling events starting at the time of feeding. These averages were then used to calculate fecal excretion and apparent digestibility of DM, OM, and N. To compare the effect of the markers with TC, data were analyzed using the MIXED procedure of SAS (SAS 9.4; SAS Institute Inc., Cary, $\mathrm{NC}$ ) with the fixed effect of diet, method (TC, iNDF, or AIA), and 2-way interaction and the random effect of block and cow within block. To compare marker and nutrient concentrations in feces between TC and SP12 or among various spot sampling frequencies (SP2, SP4, SP6, or SP12), the same model was used except spot sampling frequency was used instead of method. The fixed effect of spot sampling was analyzed as a repeated measure with a first-order autoregressive covariate structure according to the lowest Bayesian information criterion. Additionally, the effect of diet within a method or method within a diet was determined, although no significant interaction between diet and method was observed (see Results and Discussion). For this analysis, the same models above were used except that cow within block was removed, and because repeated measurements did not occur, a covariate structure was not applied. For all models, denominator degrees of freedom were adjusted using the KenwardRoger approximation. The accuracy of fecal outputs estimated using AIA and iNDF compared with TC was examined using the REG procedure of SAS (SAS 9.4; SAS Institute Inc.) where the root mean squared error was used to evaluate linearity of the regression.

\section{RESULTS AND DISCUSSION}

\section{Effect of Markers on Fecal Output and Digestibility}

An ideal marker should accurately predict fecal outputs and nutrient apparent digestibility as well as provide reliable information about the magnitude of diet effects (Huhtanen et al., 1994). The diets in the current study were designed to produce slightly different fecal outputs and then apparent DM digestibility by decreasing starch level and increasing the proportion of by-product in the diet (Pereira and Armentano, 2000; Weiss et al., 2009b). Therefore, digestibility of DM, $\mathrm{OM}$, and $\mathrm{N}$ were greater $(P \leq 0.04)$ or tended to be greater $(P=0.07)$ for CS compared with AS-K (Table $2)$. However, for fecal outputs, only numerical differences were observed $(P>0.13)$ between CS and ASK. Increasing dietary starch can decrease fecal output because increased inclusion of starch sources in a diet usually decreases the proportion of NDF sources (Weiss et al., 2009b). In addition, increasing by-product (i.e., nonforage NDF) in a diet replacing forage increased fecal NDF output and decreased DM and NDF apparent digestibility (Pereira and Armentano, 2000). However, the decrease in starch content and increase in proportion of by-product in AS-K was not enough to produce statistical differences in fecal output, although differences in apparent DM and $\mathrm{N}$ digestibility were observed with no difference in DMI in the current study. No statistical effects on fecal DM outputs may have occurred due to an associative effect between dietary starch and NDF digestibility. A meta-analysis by Ferraretto et al. (2013) showed that an increase in dietary starch concentration decreased total-tract NDF digestibility.

Differences in fecal output and apparent digestibility among methods $(P<0.01)$ were observed. When iNDF was used as a marker all variables of interest were estimated within $5 \%$ of true quantities (i.e., TC; $P>0.19)$, whereas using AIA overestimated $(P<$ 0.01) fecal outputs by 44 to $61 \%$ compared with TC and thus underestimated apparent digestibility by 16 to $32 \%$. The difference in accuracy of fecal outputs between AIA and iNDF is supported by regression analysis (Figure 1). This difference occurred because recovery of iNDF (fecal excretion/intake) was $100.4 \pm$ $11.5 \%$ (mean $\pm \mathrm{SD}$ ), whereas the recovery of AIA was $66.9 \pm 10.7 \%$ (data not shown). Differences between TC and estimated fecal output with iNDF or AIA have 
been reported previously (Huhtanen et al., 1994; Lee and Hristov, 2013). In lactating cows fed deficient or adequate $\mathrm{CP}$ diet, iNDF estimated fecal outputs and apparent digestibility more accurately compared with AIA (Lee and Hristov, 2013), which is in agreement with the current study. However, in growing bulls fed grass-based diets, DM digestibility estimated using iNDF differed from TC and was dependent on the pore size of the incubation bag used (Huhtanen et al., 1994). Since then, bags with a pore size of $25 \mu \mathrm{m}$ have been widely used (Lee et al., 2012; Morris et al., 2018; Velásquez et al., 2018), and our study confirmed that iNDF with the $25-\mu \mathrm{m}$ incubation bags accurately estimated fecal outputs and apparent digestibility of DM, $\mathrm{OM}$, and N compared with TC. When comparing AIA and TC, Lee and Hristov (2013) reported an underestimation of fecal output of approximately 15\%. These authors attributed the underestimation of fecal output with AIA to an increase in the proportion of fecal AIA to TMR AIA (i.e., an overestimation of fecal AIA ex- cretion relative to AIA intake). However, Huhtanen et al. (1994) found no difference in DM digestibility when determined with AIA compared with TC. The accuracy of AIA as a marker for estimating fecal output can be affected by various factors. The AIA content of grass is typically greater than alfalfa and concentrates (Van Soest, 1994). Thus, because of low dietary AIA content, the estimated fecal outputs in the current study and that of Lee and Hristov (2013) were likely more affected by analytical errors in determination of dietary and fecal AIA content. Indeed, the standard errors of the means of all variables from AIA were larger (2- to 3 -fold) than those from iNDF and TC in the current study. This is supported by Kanani et al. (2015), where AIA versus TC accurately estimated fecal outputs and apparent DM digestibility in cows fed bermudagrass hay as a sole forage source in the diet. Fecal AIA concentration in this study was 3 to 5 times greater than that in the current study. Furthermore, the procedure used in the present study to determine AIA (using 2

Table 2. Fecal output and apparent digestibility determined by total collection (TC) or estimated by indigestible NDF (iNDF) or acid-insoluble ash (AIA) as markers

\begin{tabular}{|c|c|c|c|c|c|c|}
\hline \multirow[b]{2}{*}{ Item $^{1}$} & \multicolumn{2}{|c|}{ Diet $^{2}$} & \multirow[b]{2}{*}{ SEM } & \multicolumn{3}{|c|}{$P$-value ${ }^{3}$} \\
\hline & CS & AS-K & & $\mathrm{D}$ & M & $\mathrm{D} \times \mathrm{M}$ \\
\hline DMI, kg/d & 21.8 & 20.9 & 1.09 & 0.48 & & \\
\hline \multicolumn{7}{|l|}{ Fecal output } \\
\hline $\mathrm{DM}, \mathrm{kg} / \mathrm{d}$ & & & & 0.31 & $<0.01$ & 0.52 \\
\hline $\mathrm{TC}^{\mathrm{b}}$ & 5.9 & 6.1 & 0.43 & 0.57 & & \\
\hline $\mathrm{iNDF}^{\mathrm{b}}$ & 5.6 & 6.3 & 0.44 & 0.19 & & \\
\hline AIA $^{\mathrm{a}}$ & 8.5 & 9.8 & 0.98 & 0.36 & & \\
\hline $\mathrm{OM}, \mathrm{kg} / \mathrm{d}$ & & & & 0.39 & $<0.01$ & 0.55 \\
\hline $\mathrm{TC}^{\mathrm{b}}$ & 5.2 & 5.4 & 0.38 & 0.74 & & \\
\hline $\mathrm{iNDF}^{\mathrm{b}}$ & 5.0 & 5.5 & 0.39 & 0.26 & & \\
\hline AIA $^{\mathrm{a}}$ & 7.6 & 8.6 & 0.85 & 0.42 & & \\
\hline $\mathrm{N}, \mathrm{g} / \mathrm{d}$ & & & & 0.13 & $<0.01$ & 0.37 \\
\hline $\mathrm{TC}^{\mathrm{b}}$ & 165 & 188 & 13.4 & 0.16 & & \\
\hline $\mathrm{iNDF}^{\mathrm{b}}$ & 158 & 193 & 12.3 & 0.057 & & \\
\hline AIA $^{\mathrm{a}}$ & 239 & 303 & 31.3 & 0.21 & & \\
\hline \multicolumn{7}{|c|}{ Apparent digestibility } \\
\hline DM, $\%$ & & & & 0.07 & $<0.01$ & 0.41 \\
\hline $\mathrm{TC}^{\mathrm{a}}$ & 72.9 & 70.8 & 1.1 & 0.24 & & \\
\hline $\mathrm{iNDF}^{\mathrm{a}}$ & 74.0 & 69.8 & 1.6 & 0.058 & & \\
\hline $\mathrm{AIA}^{\mathrm{b}}$ & 61.1 & 53.6 & 2.9 & 0.15 & & \\
\hline $\mathrm{OM}, \mathrm{kg} / \mathrm{d}$ & & & & 0.04 & $<0.01$ & 0.36 \\
\hline $\mathrm{TC}^{\mathrm{a}}$ & 74.3 & 71.7 & 1.1 & 0.16 & & \\
\hline $\mathrm{iNDF}^{\mathrm{a}}$ & 75.3 & 70.7 & 1.6 & 0.04 & & \\
\hline $\mathrm{AIA}^{\mathrm{b}}$ & 63.0 & 55.0 & 2.8 & 0.11 & & \\
\hline $\mathrm{N}, \%$ & & & & 0.01 & $<0.01$ & 0.26 \\
\hline $\mathrm{TC}^{\mathrm{a}}$ & 70.8 & 65.0 & 1.3 & 0.03 & & \\
\hline $\mathrm{iNDF}^{\mathrm{a}}$ & 72.0 & 63.8 & 1.7 & $<0.01$ & & \\
\hline AIA $^{\mathrm{b}}$ & 57.9 & 44.4 & 3.6 & 0.059 & & \\
\hline
\end{tabular}

${ }_{\mathrm{a}, \mathrm{b}}$ Average values between TC, iNDF, and AIA within a column with the same superscripts are similar $(P>$ $0.05)$.

${ }^{1}$ Marker (iNDF and AIA) concentrations were determined in feces from TC.

${ }^{2} \mathrm{CS}=$ diet containing $48.5 \%$ corn silage (DM basis); AS-K = diet containing $48.3 \%$ alfalfa silage, high byproduct, and supplemental potassium.

${ }^{3} \mathrm{D}=\operatorname{diet}(\mathrm{CS}, \mathrm{AS}-\mathrm{K}) ; \mathrm{M}=\operatorname{method}(\mathrm{TC}, \mathrm{iNDF}, \mathrm{AIA}) ; \mathrm{D} \times \mathrm{M}=$ interaction between $\mathrm{D}$ and $\mathrm{M}$. 


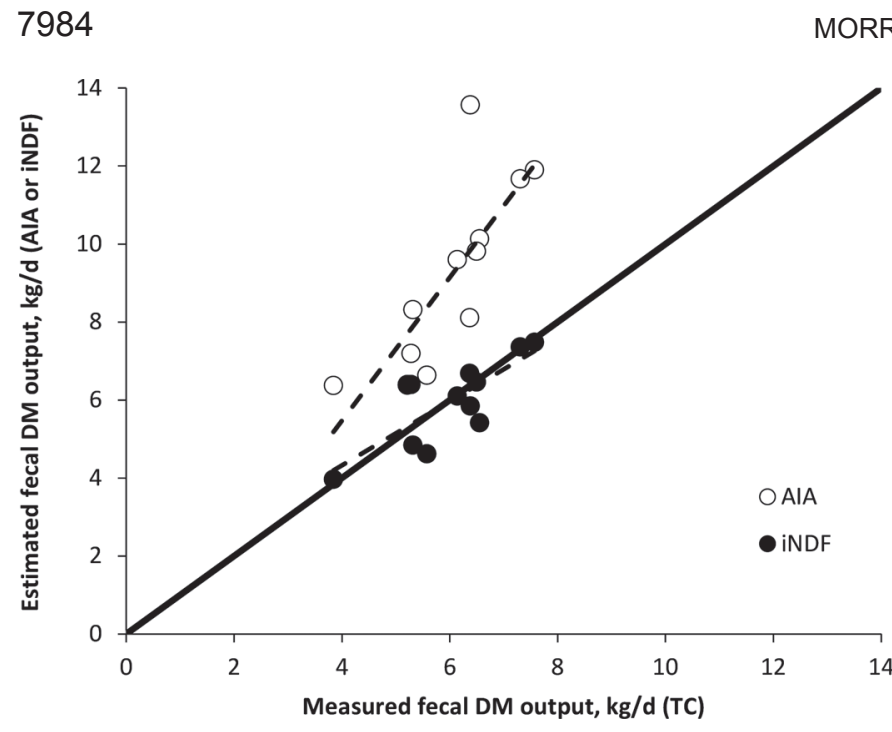

Figure 1. Relationship between fecal DM output measured (total collection; TC) and estimated [acid-insoluble ash (AIA) or indigestible $\mathrm{NDF}(\mathrm{iNDF})] . \mathrm{AIA}=1.83( \pm 0.45 ; P<0.01) \times \mathrm{TC}-1.88( \pm 2.76 ; P$ $=0.51)$; root mean squared error $=1.53$ and $P<0.13$. iNDF $=0.82$ $( \pm 0.21 ; P<0.01) \times \mathrm{TC}+1.03( \pm 1.28 ; P=0.44) ;$ root mean squared error $=0.71$ and $P<0.01$. The solid line is $\mathrm{Y}=\mathrm{X}$.

$N \mathrm{HCl}$; Van Keulen and Young, 1977) is susceptible to incomplete recovery of silica due to a lack of sufficient acid dehydration (Van Soest et al., 1991). Furthermore, as Lee and Hristov (2013) pointed out, forages can be contaminated with soil during harvest (Wallsten and Martinsson, 2009). Unexpected sources of AIA in the feeding can result in erroneous estimation of fecal outputs (Van Soest, 1994). Van Keulen and Young (1977) reported an AIA recovery of $84 \%$ when an alfalfa hay, barley, and oat diet was contaminated with sand (i.e., soil contamination). However, because iNDF accurately estimated fecal output and soil contamination can influence NDF content via increased neutral detergentinsoluble ash (Mertens, 2016), soil contamination was likely not the only factor contributing to overestimation of fecal output with AIA as a marker. Rather, a combination of the aforementioned factors likely contributed to the imprecision in estimating fecal output with AIA in the current study.

Although diet $\times$ method interactions were not observed $(P>0.26$; Table 2$)$, because our objective was to determine whether markers accurately predict magnitude and direction of dietary effects, we determined diet effects within method. For TC, dietary effects on fecal outputs and digestibilities were not observed $(P$ $>0.16)$ except for an increase $(P=0.03)$ in apparent digestibility of $\mathrm{N}$ for $\mathrm{CS}$ versus AS-K (70.8 vs. 65.0). However, although iNDF agreed with TC in the direction of dietary effects, the magnitude of difference in most variables between diets was greater for iNDF than for TC, which resulted in a discrepancy in the interpretation of dietary effects. Specifically, CS compared with AS-K for iNDF tended to decrease $(P=0.057)$ fecal N output, tended to increase $(P=0.058)$ DM apparent digestibility, and increased $(P<0.04) \mathrm{OM}$ and $\mathrm{N}$ apparent digestibility. This discrepancy between TC and iNDF was driven by a numerical underestimation of fecal DM output for the CS diet (5.6 vs. $5.9 \mathrm{~kg}$ ) and a numerical overestimation for the AS-K diet (6.3 vs. $6.1 \mathrm{~kg}$ ) for iNDF compared with TC. Lee and Hristov (2013) reported dietary effects on marker-estimated fecal outputs. Specifically, a numerical underestimation of fecal DM output of $6 \%$ occurred in the high-CP diet and a significant overestimation of fecal DM output of $7 \%$ occurred in the low-CP diet when comparing estimated fecal output with iNDF to TC. This resulted in significant dietary effects on DM, OM, and N apparent digestibility when estimated via iNDF compared with nonsignificant effects via TC. Overall, our results are in agreement with the conclusion by Lee and Hristov (2013) that estimation of fecal output and DM, OM, and $\mathrm{N}$ apparent digestibility was more reliable using iNDF versus AIA. However, the discrepancy between

Table 3. Effect of total collection (TC) or spot sampling frequencies of 12 evenly spaced events starting at feeding time (SP12) on fecal content of indigestible NDF (iNDF), acid-insoluble ash (AIA), OM, and N (\% of $\mathrm{DM})$

\begin{tabular}{|c|c|c|c|c|c|c|c|c|}
\hline \multirow[b]{2}{*}{ Item } & \multicolumn{2}{|c|}{$\mathrm{TC}$} & \multicolumn{2}{|c|}{ SP12 } & \multirow[b]{2}{*}{ SEM } & \multicolumn{3}{|c|}{$P$-value ${ }^{1}$} \\
\hline & $\mathrm{CS}^{2}$ & AS-K ${ }^{2}$ & CS & AS-K & & D & M & $\mathrm{D} \times \mathrm{M}$ \\
\hline iNDF & 26.3 & 32.8 & 27.2 & 33.6 & 1.8 & 0.04 & 0.36 & 0.95 \\
\hline AIA & 1.71 & 1.19 & 1.86 & 1.27 & 0.08 & $<0.01$ & $<0.01$ & 0.19 \\
\hline $\mathrm{OM}$ & 89.0 & 87.4 & 88.9 & 88.1 & 0.22 & $<0.01$ & 0.11 & 0.06 \\
\hline $\mathrm{N}$ & 2.81 & 3.08 & 2.77 & 3.09 & 0.05 & $<0.01$ & 0.66 & 0.57 \\
\hline
\end{tabular}

${ }^{1} \mathrm{D}=\operatorname{diet}(\mathrm{CS}, \mathrm{AS}-\mathrm{K}) ; \mathrm{M}=\operatorname{method}(\mathrm{TC}, \mathrm{iNDF}, \mathrm{AIA}) ; \mathrm{D} \times \mathrm{M}=$ interaction between $\mathrm{D}$ and $\mathrm{M}$.

${ }^{2} \mathrm{CS}=$ diet containing $48.5 \%$ corn silage (DM basis); AS-K = diet containing $48.3 \%$ alfalfa silage, high byproduct, and supplemental potassium. 
dietary effects should be considered and further investigated when fecal outputs and nutrient digestibility are estimated using markers.

Compared with TC, using AIA as an intrinsic fecal marker increased the magnitude of difference between the diets for most variables; however, dietary effects (i.e., level of significance) were not different between AIA and TC for all variables except apparent $\mathrm{N}$ digest- ibility. This occurred due to an increase in variation (i.e., SEM) by more than 2 -fold in all response variables for AIA compared with TC. The larger variation for AIA likely explains the lack of method $x$ diet interactions in the current study and further justifies the examination of diet effects within method. However, it is worth noting that although our results generally agreed with the results by Lee and Hristov (2013), the
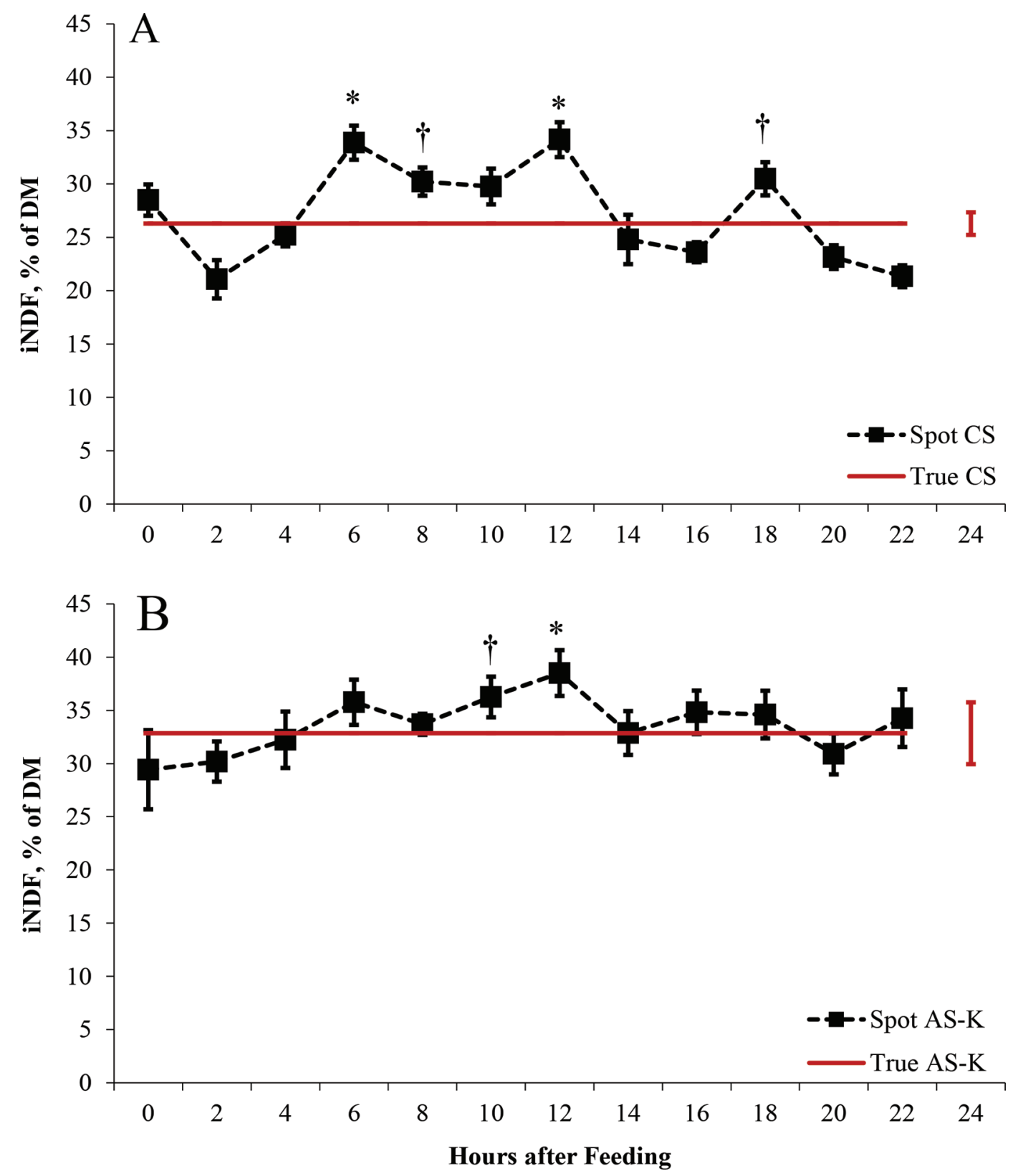

Figure 2. Diurnal variation in fecal indigestible NDF (iNDF) content for (A) the corn silage-based diet (CS) and (B) the alfalfa silage-based diet with high by-product and supplemental potassium (AS-K). Error bars indicate standard errors of values at each time point and a standard error of true marker content (iNDF concentration from total collection). Significance at each time point is included ( $† P<0.10, * P<0.05$ ). Color version available online. 
current study had only 12 observations per method in a randomized block design, probably needing confirmation by more studies.

\section{Effect of Sampling Frequency on Representation of Marker and Nutrient Composition}

Feces from spot sampling at a frequency of 12 events (i.e., every $2 \mathrm{~h}$ in a 24 -h cycle) compared with that from TC resulted in similar $(P>0.11)$ fecal iNDF, $\mathrm{OM}$, and $\mathrm{N}$ content (Table 3 ). These results indicate that samples from 12 sampling events can accurately estimate fecal output and apparent DM, OM, and $\mathrm{N}$ digestibility using iNDF as a marker. In contrast, AIA concentration of feces from SP12 was greater $(P$ $<0.01$ ) by $7.9 \%$ compared with that from TC. The reason for the greater fecal AIA concentration in feces from spot sampling versus TC is unclear; however, this
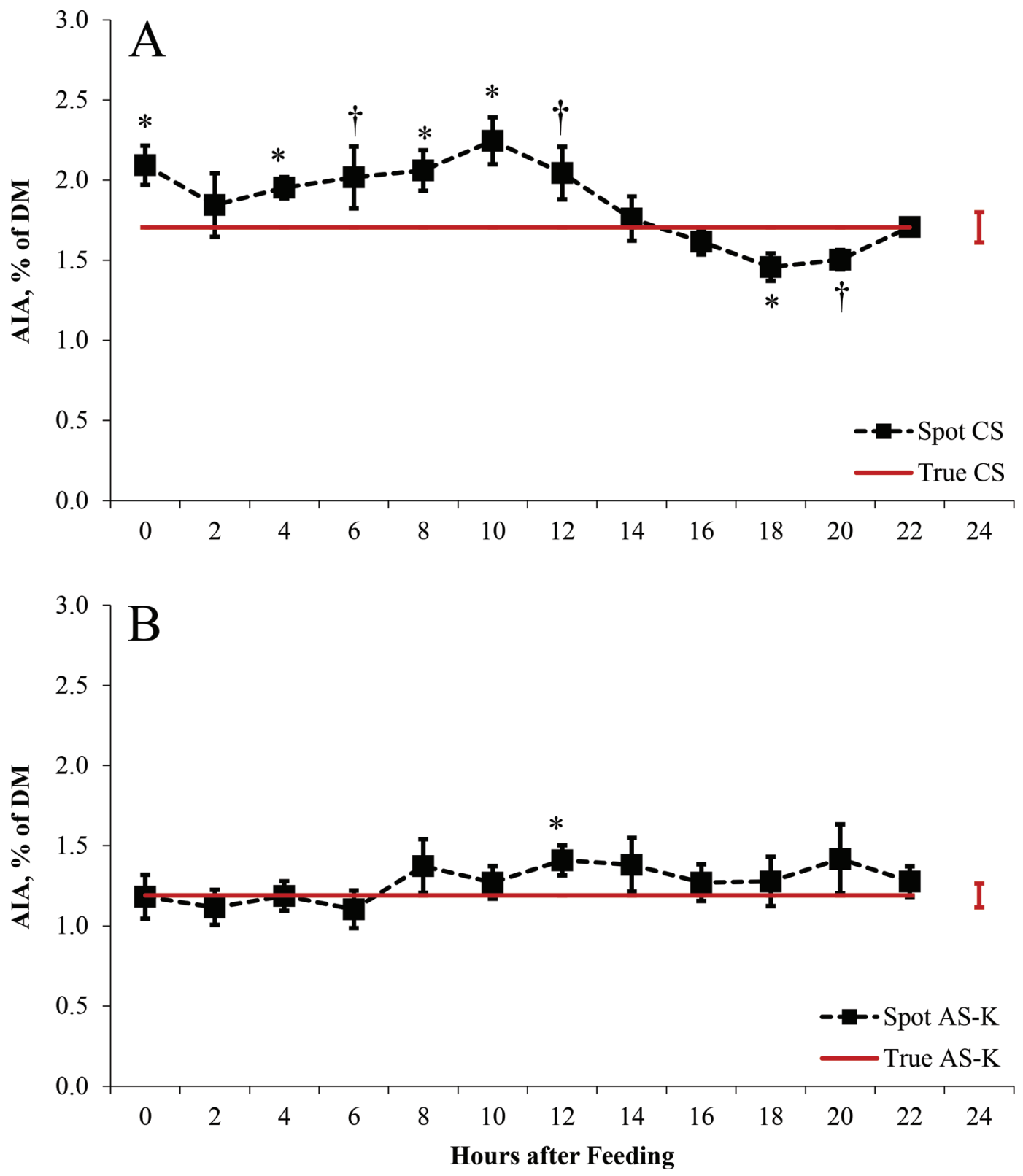

Figure 3. Diurnal variation in fecal acid-insoluble ash (AIA) content for (A) the corn silage-based diet (CS) and (B) the alfalfa silage-based diet with high by-product and supplemental potassium (AS-K). Error bars indicate standard errors of values at each time point and a standard error of true marker content (AIA concentration from total collection). Significance at each time point is included ( $P$ P $\left.0.10,{ }^{*} P<0.05\right)$. Color version available online. 
can partially explain overestimation of fecal outputs and underestimation of apparent digestibility compared with TC.

Diurnal variation in both iNDF and AIA marker content occurred (Figures 2 and 3). This variation was more pronounced in cows consuming CS. Few studies have examined diurnal variation in fecal excretion of intrinsic markers. Van Keulen and Young (1977) found minimal diurnal variation in the digestibility coefficient calculated using AIA from bihourly fecal spot samples in sheep. However, several classic studies using $\mathrm{Cr}_{2} \mathrm{O}_{3}$ or lignin as markers indicated significant diurnal variation in marker excretion (Kane et al., 1952; Kameoka et al., 1956; Hardison et al., 1959). Ideal markers should move through the digestive tract with the analyte of interest (Van Soest, 1994). However, the current results would suggest potential variation in the flux of iNDF and AIA via the digestive tract. Because intrinsic markers (e.g., iNDF, AIA, lignin) are primarily associated with both large and small fiber particles, variation in flux from the rumen to the lower gut could occur throughout the day due to differences in intrinsic marker intakes (i.e., sorting behavior, especially for once-daily feeding) and rumen passages between large and small particles (Bayat et al., 2010). In addition, the inherent eating behavior of dairy cows can explain the diurnal variation in fecal marker concentration (Kononoff et al., 2003). However, the reason for increased diurnal variation in marker excretion for cows fed CS versus AS-K is unknown. This response could be associated with a decrease in meal size and intermeal interval that can be caused by more glucogenic diets (Oba and Allen, 2003; Allen et al., 2009). A more sporadic eating behavior could cause an increase in variation in passage of particles (i.e., markers) from the rumen. However, Kanani et al. $(2014,2015)$ found no diurnal variations of fecal AIA in cows fed a diet containing bermudagrass hay. In this study, however, only 4 spot samples were conducted to examine diurnal variations of AIA, and the major component of the diet was likely grass hay (NDF, $73 \%$ in dietary DM; dietary composition was not published in this study).

To determine the optimal number of spot sampling that minimizes frequency while maintaining accuracy, data from individual spot samples were composited to represent SP12, SP6, SP4, and SP2 (Table 4). Because diurnal variation in marker output might be influenced by feeding behavior, the intervals were based on feeding time. Fecal iNDF content increased with decreasing spot sampling frequency for CS, whereas the AS-K diet was not affected by spot sampling frequency, causing the interaction of diet $\times$ sampling frequency $(P<$ 0.01). For iNDF in the CS diet, SP6 did not differ $(P$ $=0.70)$ from SP12, whereas SP4 and SP2 produced fecal iNDF contents that were 10 and $15 \%$ greater than SP12 $(P<0.01)$, respectively. Acid-insoluble ash content tended to differ $(P=0.06)$ by diet and method. Similar to iNDF, this interaction occurred such that spot sampling frequency did not affect AIA concentration in feces for AS-K but did influence $(P<0.01)$ fecal AIA content for CS. Furthermore, when AIA was used, SP6 and SP4 did not differ $(P>0.27)$ from SP12 for

Table 4. Effects of spot sampling frequency on fecal indigestible NDF (iNDF), acid-insoluble ash (AIA), OM, and $\mathrm{N}$ content $(\%$ of $\mathrm{DM})$

\begin{tabular}{|c|c|c|c|c|c|c|c|c|}
\hline \multirow[b]{2}{*}{ Item $^{1}$} & \multicolumn{4}{|c|}{ Time point ${ }^{2}$} & \multirow[b]{2}{*}{ SEM } & \multicolumn{3}{|c|}{$P$-value ${ }^{3}$} \\
\hline & SP12 & SP6 & $\mathrm{SP} 4$ & SP2 & & D & TP & $\mathrm{D} \times \mathrm{TP}$ \\
\hline iNDF & & & & & & 0.105 & $<0.01$ & $<0.01$ \\
\hline CS & $27.2^{\mathrm{b}}$ & $27.5^{\mathrm{b}}$ & $29.9^{\mathrm{a}}$ & $31.3^{\mathrm{a}}$ & 1.09 & $<0.01$ & & \\
\hline AS-K & 33.6 & 33.3 & 33.6 & 34.0 & 2.33 & 0.86 & & \\
\hline AIA & & & & & & $<0.01$ & 0.03 & 0.06 \\
\hline CS & $1.86^{\mathrm{b}}$ & $1.88^{\mathrm{b}}$ & $1.91^{\mathrm{b}}$ & $2.07^{\mathrm{a}}$ & 0.078 & $<0.01$ & & \\
\hline AS-K & 1.27 & 1.31 & 1.28 & 1.30 & 0.104 & 0.94 & & \\
\hline OM & & & & & & 0.19 & 0.48 & 0.33 \\
\hline CS & 88.9 & 88.9 & 88.4 & 88.6 & 0.48 & 0.37 & & \\
\hline AS-K & 88.1 & 88.0 & 88.1 & 87.9 & 0.22 & 0.62 & & \\
\hline $\mathrm{N}$ & & & & & & $<0.01$ & $<0.01$ & 0.43 \\
\hline CS & $2.77^{\mathrm{a}}$ & $2.74^{\mathrm{a}}$ & $2.64^{\mathrm{b}}$ & $2.63^{\mathrm{b}}$ & 0.069 & $<0.01$ & & \\
\hline AS-K & 3.09 & 3.11 & 3.03 & 3.02 & 0.071 & 0.09 & & \\
\hline
\end{tabular}

${ }^{\mathrm{a}, \mathrm{b}}$ Values within the same row for TP with the same superscripts are similar $(P>0.05)$.

${ }^{1} \mathrm{CS}=$ corn silage-based diet; AS-K = alfalfa silage-based diet with high by-product and supplemental potassium.

${ }^{2} \mathrm{SP} 12,6,4$, and 2 are the composite fecal samples obtained with an equally spaced spot sampling frequency of $12,6,4$, and 2 , respectively, in a 24 -h cycle.

${ }^{3} \mathrm{D}=\operatorname{diet}(\mathrm{CS}, \mathrm{AS}-\mathrm{K}) ; \mathrm{TP}=$ time point $(\mathrm{SP} 12, \mathrm{SP} 6, \mathrm{SP} 4$, and SP2); $\times \mathrm{TP}=$ interaction between $\mathrm{D}$ and $\mathrm{TP}$. 
CS, whereas SP2 produced a fecal AIA content that was $11 \%$ greater $(P<0.01)$ than SP12. For fecal N, decreasing spot sampling frequency resulted in lower fecal $\mathrm{N}$ concentration $(P<0.01)$ in cows fed the CS diet. Compared with SP12, SP6 did not differ $(P=$ $0.35)$ in estimated fecal N content; however, SP4 and SP2 underestimated $(P<0.01)$ fecal $\mathrm{N}$ by $5 \%$. The effect of spot sampling frequency on fecal marker content indicates the importance of multiple sampling that captures the diurnal variation in fecal maker content. The current study indicates that at least 6 sampling events (equally spaced from feeding time) were needed to obtain representative marker and $\mathrm{N}$ concentration in feces of cows fed the CS diet. However, more studies with various diets are needed to confirm our results.

\section{CONCLUSIONS}

Fecal output and apparent DM, OM, and $\mathrm{N}$ digestibility estimated using iNDF were similar to TC, whereas AIA overestimated fecal outputs and underestimated apparent digestibility of DM, OM, and $\mathrm{N}$. However, interpretation of dietary effects was not consistent between TC and iNDF and should be considered when iNDF is used as a digestibility marker. Diurnal variation in fecal marker concentration occurred, particularly for CS compared with AS-K, indicating that dietary composition influences the representation of fecal marker concentration. For sampling frequency, 6 spot sampling events (equally spaced from feeding time) were required to account for diurnal variation in fecal marker and nutrient concentrations. Therefore, the current study suggests the use of iNDF as an intrinsic fecal marker with at least 6 sampling events (every $4 \mathrm{~h}$ in a 24 -h cycle) when estimating fecal outputs and nutrient digestibility.

\section{ACKNOWLEDGMENTS}

The authors thank the Krauss Dairy Farm (Wooster, $\mathrm{OH})$ staff for care of the experimental animals. The experiment was partially supported by Hatch funds administered by the USDA (Washington, DC) and the Department of Animal Sciences at The Ohio State University.

\section{REFERENCES}

Allen, M. S., B. J. Bradford, and M. Oba. 2009. Board-invited review: The hepatic oxidation theory of the control of feed intake and its application to ruminants. J. Anim. Sci. 87:3317-3334.

Bayat, A. R., M. Rinne, K. Kuoppala, S. Ahvenjärvi, A. Vanhatalo, and P. Huhtanen. 2010. Ruminal large and small particle kinetics in dairy cows fed red clover and grass silages harvested at two stages of growth. Anim. Feed Sci. Technol. 155:86-98.

Colmenero, J. J., and G. Broderick. 2006. Effect of dietary crude protein concentration on milk production and nitrogen utilization in lactating dairy cows. J. Dairy Sci. 89:1704-1712.

Ferraretto, L. F., P. M. Crump, and R. D. Shaver. 2013. Effect of cereal grain type and corn grain harvesting and processing methods on intake, digestion, and milk production by dairy cows through a meta-analysis. J. Dairy Sci. 96:533-550.

Hardison, W., W. Linkous, R. Engel, and G. Graf. 1959. Observations on the use of chromic oxide for estimating the fecal output of dairy animals. J. Dairy Sci. 42:346-352.

Harvatine, K. J., and M. S. Allen. 2006. Effects of fatty acid supplements on ruminal and total tract nutrient digestion in lactating dairy cows. J. Dairy Sci. 89:1092-1103.

Huhtanen, P., K. Kaustell, and S. Jaakkola. 1994. The use of interna markers to predict total digestibility and duodenal flow of nutrients in cattle given six different diets. Anim. Feed Sci. Technol. $48: 211-227$

Kameoka, K. S. Takahashi, and H. Morimoto. 1956. Variation in the excretion of chromic oxide by ruminants. J. Dairy Sci. 39:462-467.

Kanani, J., D. Philipp, K. P. Coffey, E. B. Kegley, C. P. West, S. Gadberry, J. Jennings, A. N. Young, and R. T. Rhein. 2014. Comparison of acid-detergent lignin, alkaline-peroxided lignin, and acid-detergent insoluble ash as internal markers for predicting fecal output and digestibility by cattle offered bermudagrass hays of varying nutrient composition. J. Anim. Sci. Biotechnol. 5:7-14.

Kanani, J., D. Philipp, K. P. Coffey, E. B. Kegley, C. P. West, S. Gadberry, J. Jennings, A. N. Young, and R. T. Rhein. 2015. Diurnal variation in fecal concentrations of acid-detergent insoluble ash and alkaline-peroxide lignin from cattle fed bermudagrass hays of varying nutrient content. J. Anim. Sci. Biotechnol. 6:24-29.

Kane, E. A., W. C. Jacobson, and L. A. Moore. 1952. Diurnal variation in the excretion of chromium oxide and lignin. J. Nutr. 47:263-273.

Kononoff, P. J., A. J. Heinrichs, and H. A. Lehman. 2003. The effect of corn silage particle size on eating behavior, chewing activities, and rumen fermentation in lactating dairy cows. J. Dairy Sci. $86: 3343-3353$

Lee, C., and A. N. Hristov. 2013. Short communication: Evaluation of acid-insoluble ash and indigestible neutral detergent fiber as total-tract digestibility markers in dairy cows fed corn silage-based diets. J. Dairy Sci. 96:5295-5299.

Lee, C., A. N. Hristov, K. S. Heyler, T. W. Cassidy, H. Lapierre, G. A Varga, and C. Parys. 2012. Effects of metabolizable protein supply and amino acid supplementation on nitrogen utilization, milk production, and ammonia emissions from manure in dairy cows. J. Dairy Sci. 95:5253-5268.

Mertens, D. R. 2016. Ash-free fiber (aNDFom): Why the change and what are the consequences? Pages 96-100 in Proc. 4-State Applied Nutr. Mgmt. Conf., La Crosse, WI. Midwest Plan Service Iowa State University, Ames.

Morris, D. L., S. H. Kim, P. J. Kononoff, and C. Lee. 2018. Continuous 11-week feeding of reduced-fat distillers grains with and without monensin reduces lactation performance of dairy cows. J. Dairy Sci. 101:5971-5983.

Nennich, T. D., J. H. Harrison, L. M. VanWieringen, N. R. St-Pierre, R. L. Kincaid, M. A. Wattiaux, D. L. Davidson, and E. Block. 2006. Prediction and evaluation of urine and urinary nitrogen and mineral excretion from dairy cattle. J. Dairy Sci. 89:353-364.

Oba, M., and M. Allen. 2003. Effects of corn grain conservation method on feeding behavior and productivity of lactating dairy cows at two dietary starch concentrations. J. Dairy Sci. 86:174-183.

Pereira, M. N., and L. E. Armentano. 2000. Partial replacement of forage with nonforage fiber sources in lactating cow diets. II. Digestion and rumen function. J. Dairy Sci. 83:2876-2887.

Sampaio, C. B., E. Detmann, T. N. P. Valente, V. A. C. Costa, S. C. Valadares Filho, and A. C. Queiroz. 2011. Fecal excretion patterns and short term bias of internal and external markers in a digestion assay with cattle. Rev. Bras. Zootec. 40:657-665. 
Schneider, B. H., and W. P. Flatt. 1975. The Evaluation of Feeds Through Digestibility Experiments. University of Georgia Press, Athens.

Van Keulen, J., and B. A. Young. 1977. Evaluation of acid-insoluble ash as a natural marker in ruminant digestibility studies. J. Anim. Sci. 44:282-287.

Van Soest, P. J. 1994. Nutritional Ecology of the Ruminant. Cornell University Press, Ithaca, NY.

Van Soest, P. J., J. B. Robertson, and B. A. Lewis. 1991. Methods for dietary fiber, neutral detergent fiber, and nonstarch polysaccharides in relation to animal nutrition. J. Dairy Sci. 74:3583-3597.

Velásquez, A. V., G. G. da Silva, D. O. Sousa, C. A. Oliveira, C. Martins, P. P. M. Dos Santos, J. C. C. Balieiro, F. P. Renno, and R. S. Fukushima. 2018. Evaluating internal and external markers versus fecal sampling procedure interactions when estimating intake in dairy cows consuming a corn silage-based diet. J. Dairy Sci. 101:1-12.

Wallsten, J., and K. Martinsson. 2009. Effects of maturity stage and feeding strategy of whole crop barley silage on intake, digestibility and milk production in dairy cows. Livest. Sci. 121:155-161.

Weiss, W. P., N. R. St-Pierre, and L. B. Willett. 2009a. Varying type of forage, concentration of metabolizable protein, and source of carbohydrate affects nutrient digestibility and production by dairy cows. J. Dairy Sci. 92:5595-5606.

Weiss, W. P., L. B. Willett, N. R. St-Pierre, D. C. Borger, T. R. McKelvey, and D. J. Wyatt. 2009b. Varying forage type, metabolizable protein concentration, and carbohydrate source affects manure excretion, manure ammonia, and nitrogen metabolism of dairy cows. J. Dairy Sci. 92:5607-5619. 